\title{
Association of APEX1 and OGG1 gene polymorphisms with breast cancer risk among Han women in the Gansu Province of China
}

Tao Wang ${ }^{1}$, Haitao Wang ${ }^{1}$, Suisheng Yang ${ }^{2}$, Hongyun Guo ${ }^{1}$, Binming Zhang ${ }^{2}$, Huan Guo', Lan Wang', Gongjian Zhu', Yongdong Zhang ${ }^{1}$, Haihong Zhou', Xiuli Zhang ${ }^{1}$, Haining $\mathrm{Li}^{1}$ and Haixiang Su ${ }^{1 *}$ (D)

\begin{abstract}
Background: Genetic variations in key DNA repair genes may influence DNA repair capacity, DNA damage and breast carcinogenesis. The current study aimed to estimate the association of APEX1 and OGG1 polymorphisms with the risk of breast cancer development.

Methods: A total of 518 patients with histopathologically confirmed breast cancer and 921 region- and age-matched cancer-free controls were genotyped for the APEX1 polymorphisms rs3136817 and rs1130409 and the OGG1 polymorphisms rs1052133 and rs2072668 using a QuantStudio ${ }^{\text {TM }} 12$ K Flex Real-Time PCR System.

Results: The rs3136817 heterozygous TC genotype along with the rs3136817 dominant model (TC + CC) was strongly associated with breast cancer susceptibility (odds ratio [OR] $=0.670,95 \%$ confidence interval $[95 \% \mathrm{Cl}]$ : $0.513-0.873, P=0.003 ; \mathrm{OR}=0.682,95 \% \mathrm{Cl}: 0.526-0.883, P=0.004$, respectively). No significant associations were observed among rs1 130409, rs1052133, rs2072668 and breast cancer risk. Furthermore, an allele combination analysis revealed that APEX1 haplotypes containing C-T (alleles rs3136817 and rs1130409) conferred a significantly lower risk (corrected $P<0.001$ ).
\end{abstract}

Conclusion: This research is the latest report showing that an APEX1 rs3136817 heterozygous genotype may have a positive influence on DNA repair capacity in patients with breast cancer and thus may have a potential protective effect for Chinese Han women.

Keywords: APEX1, OGG1, Polymorphisms, Haplotype, Breast cancer

\section{Background}

A recent epidemiological report from the National Central Cancer Registry (NCCR) of China showed that breast cancer is the most commonly diagnosed cancer among women in China. For female breast cancer, the 5-year survival rate (73\%) in China is considerably reduced compared with corresponding estimates in Australia (89\%) and the United States $(90 \%)$ and to a lesser degree in Europe (82\%) [1]. Breast cancer ranks as the sixth leading cause of cancer

\footnotetext{
* Correspondence: haixiang001@hotmail.com

${ }^{1}$ Research Center of Translational Medicine, Gansu Provincial Academic Institute for Medical Research, NO. 2 Xiaoxihu East Street, Lanzhou, Gansu 730050, People's Republic of China

Full list of author information is available at the end of the article
}

deaths among women in rural areas of China, while the incidence rate $(37.86 / 100,000)$ is continually increasing [2]. Numerous breast cancer susceptibility genes have been identified by molecular epidemiological studies of cancer (e.g., BRCA1/2, TP53, PTEN and ATM). BRCA1 and $B R C A 2$ mutations comprise 32 to $82 \%$ of hereditary breast cancer cases [3]. The prevalence of these mutations, however, is considerably reduced in the Chinese population. For example, BRCA1 and BRCA2 mutations contribute to only $10 \%$ of hereditary breast cancer cases $[4,5]$. Thus, identification of other novel susceptibility loci among Chinese breast cancer patients is needed. Analyses of genetic polymorphisms reveal correlations between breast cancer susceptibility and many loci $[6,7]$. Recently,

(c) The Author(s). 2018 Open Access This article is distributed under the terms of the Creative Commons Attribution 4.0 International License (http://creativecommons.org/licenses/by/4.0/), which permits unrestricted use, distribution, and reproduction in any medium, provided you give appropriate credit to the original author(s) and the source, provide a link to the Creative Commons license, and indicate if changes were made. The Creative Commons Public Domain Dedication waiver (http://creativecommons.org/publicdomain/zero/1.0/) applies to the data made available in this article, unless otherwise stated. 
a considerable number of novel polymorphic variants have been identified by genome-wide association studies (GWAS) for breast cancer susceptibility [8, 9].

DNA repair systems act to safeguard the integrity of the genome against damage caused by exogenous and endogenous carcinogens and by mutagens. Defects in DNA repair capability can increase the risk of carcinogenesis [10], including breast cancer. Patients with breast cancer exhibit significantly reduced DNA repair proficiency [11]. The high accumulation of DNA damage may cause the initiation of carcinogenesis and aberrant cell division [12]. Additionally, several base excision repair (BER) enzymes may also participate in the regulation of other biological processes, including BER, cell cycle progression [13], transcription initiation [14] and apoptosis [15]. Moreover, 8-oxoguanine DNA glycosylase 1 (OGG1) and apurinic/ apyrimidinic endonuclease 1 (APEX1) are key enzymes in the BER pathway of oxidative DNA damage, excising abasic residues. OGG1 is a glycosidase that hydrolyzes the bonds between damaged bases and the sugar-phosphate backbone in DNA, creating an abasic site, while the endonuclease APEX1 cleaves the $5^{\prime}$ end of the abasic site. Mutations in these genes are expected to lead to a mutation-prone phenotype and contribute to tumor formation [16]. In recent years, studies of breast cancer and DNA repair have emphasized the relationship between different single nucleotide polymorphisms (SNPs) in DNA repair-related genes and the probability of developing carcinoma. Kim et al. [17] reported that the combined effect of APEX1 Asp148Glu was associated with an increased risk of breast cancer in a Korean population. Likewise, Roberts et al. [18] drew the conclusion that SNPs in nucleotide excision repair (NER) genes and BER genes affect the risk of developing breast cancer. Work by Smith et al. [19] demonstrated only a slight positive association between individual DNA repair genotypes and breast cancer risk; however, the combined effects of multiple polymorphisms in DNA repair pathways may be more noteworthy.

The present work aimed to investigate whether APEX1 and $O G G 1$ gene polymorphisms (frequency $\geq 5 \%$ ) exert any synergistic effects on breast cancer risk. Using HapMap data, we selected four putative functional tag SNPs in APEX1 (rs1130409 and rs3136817) and OGG1 (rs1052133 and rs2072668) and further evaluated the genetic interactions of these four polymorphisms and their relation to breast cancer risk among the study population of Han women living in the Gansu area in Northwest China.

\section{Methods}

\section{Study participants and data collection}

A total of 518 histopathologically confirmed patients with breast cancer were enrolled in this study from the Gansu Provincial Cancer Hospital (Gansu Province, China) between December 2014 and August 2017. None of these patients had been previously treated with systemic therapy. For the age- and region-matched controls, 921 cancer-free women were randomly selected from the Health Examination Surveys conducted in the same hospital. Inclusion criteria included negative history of all forms of cancer and no family history of breast cancer. All related data were drawn from questionnaires (see Additional file 1) and the patients' medical charts. Informed consent was obtained from all individual participants, and this research was approved by the ethical committee of the Gansu Provincial Academic Institute for Medical Research and Gansu Provincial Cancer Hospital (IRB number: A201412040036).

\section{SNP identification and selection}

Details of the SNP identification and selection have been described previously [20]. Briefly, tag SNPs can be used to identify most genetic variations existing in a gene and develop markers to assess the relationship between a disease and a specific region, regardless of whether the tag SNPs have functional effects [21]. Employing selection for tagger pairing processes, tag SNPs were selected from the HapMap CHB database (HapMap Data Rel 24/phase II Nov08). Tag SNPs were chosen by using Haploview version 4.0 software according to the following selection criteria: minor allele frequency (MAF) $\geq 0.05$ and pair-wise $\mathrm{r}^{2} \geq 0.8$. Finally, the APEX1 polymorphisms rs1130409 and rs3136817 and the OGG1 polymorphisms rs1052133 and rs2072668 were selected.

\section{Genotyping method}

A total of $5 \mathrm{~mL}$ of peripheral blood was collected in tubes containing EDTA from each of the participants for genomic DNA extraction using the genomic DNA Extraction Kit VER.3.0 according to the manufacturer's instructions (TaKaRa Biotechnology, China). The DNA samples had A260/A230 ratios from 1.9 to 2.0 and A260/A280 ratios from 1.7 to 1.9; the concentrations of the samples were adjusted to $50 \mathrm{ng} / \mu \mathrm{l}$. DNase/RNasefree distilled water was used in each assay as a nontemplate control (NTC). The multiplex TaqMan assays for genotyping were performed using the QuantStudio ${ }^{\mathrm{m}}$ 12 K Flex Real-Time PCR System (Applied Biosystems, CA, USA) according to the manufacturer's recommended operating conditions. The genotype data were analyzed using the OpenArray ${ }^{\circ}$ SNP Genotyping Analysis software (version 1.0.5) (Applied Biosystems, CA, USA). To evaluate quality control, all genotyping assays were blind to the subject status. In addition, the reproducibility of genotyping was evaluated by direct sequencing in $20 \%$ of the samples randomly selected from each SNP and reached $100 \%$. 


\section{Statistical analysis}

To assess the deviation of the genotype frequencies of the four tag SNPs from Hardy-Weinberg equilibrium (HWE) in the control subjects, the chi-square goodness-of-fit test was used. The distribution of the APEX1 and OGG1 genotypes were compared between controls and patients using Pearson's chi-square test (goodness-of-fit) or Fisher's exact test. For the association tests, multivariate unconditional logistic regression adjusting for age was performed to estimate odds ratios (ORs) and 95\% confidence intervals (CIs) for the associations of the APEX1 and OGG1 polymorphisms with breast cancer risk and clinicopathologic features. As reported previously, classical genetic models, including dominant models and recessive models, were used to analyze the associations [22]. The frequency distributions of the APEX1 and OGG1 haplotypes were estimated using SHEsis online software (http://analysis.bio-x. cn/myanalysis.php) [23, 24].

To identify potential gene-gene interactions, we employed the multifactor dimensionality reduction (MDR) method (http://www.epistasis.org) to evaluate the best cross-group model for further confirmation. MDR is a robust and novel data-mining approach that was applied as described previously $[25,26]$. Briefly, this method converts two or more discrete genetic variables to a single attribute. The aim of this approach is to identify the overall best combination all loci. With MDR, the newly formed onedimensional variable can be assessed to predict disease status using cross-validation and permutation testing corrections by repeating the entire analysis on 1000 datasets. Furthermore, a final best MDR model is chosen that simultaneously has the maximal testing accuracy and cross-validation consistency (CVC).

To avoid false-positive results, haplotypes with frequencies greater than $3 \%$ were considered in all of the research participants. Bonferroni correction was employed to make the adjustment for multiple comparisons. All statistical analyses were performed using SPSS software (version 16.0), and differences were considered significant at $P<0.05$.

\section{Results}

\section{Demographic and pathological characteristics}

All the detailed clinical and pathological characteristics of the study participants are presented in Table 1. The average age of the breast cancer patients was 49.3 (standard deviation $[\mathrm{SD}]=8.2$ ), and the average age of the controls was 48.4 years $(\mathrm{SD}=8.9)$. No significant differences were observed between the two groups with respect to mean age and age distribution $(P>0.064)$. The distribution of all four SNPs in the control subjects obeyed the predicted Hardy-Weinberg equilibrium values $(P>0.05)$.
Table 1 Characteristics in breast cancer cases

\begin{tabular}{|c|c|}
\hline Characteristics & Cases (\%) \\
\hline \multicolumn{2}{|l|}{ LN involvement } \\
\hline Positive & 179 (34.56) \\
\hline Negative & $237(45.75)$ \\
\hline Unknown & 102 (19.69) \\
\hline \multicolumn{2}{|l|}{ ER } \\
\hline Positive & $330(63.71)$ \\
\hline Negative & $170(32.82)$ \\
\hline Unknown & $18(3.47)$ \\
\hline \multicolumn{2}{|l|}{$P R$} \\
\hline Positive & $266(51.35)$ \\
\hline Negative & $230(44.40)$ \\
\hline Unknown & $22(4.25)$ \\
\hline \multicolumn{2}{|l|}{ P53 } \\
\hline Positive & 199 (38.42) \\
\hline Negative & 267 (51.54) \\
\hline Unknown & $52(10.04)$ \\
\hline \multicolumn{2}{|l|}{ Her-2 } \\
\hline Positive & 117 (22.59) \\
\hline Negative & 379 (73.17) \\
\hline Unknown & $22(4.25)$ \\
\hline \multicolumn{2}{|l|}{ Ki-67 } \\
\hline Positive & $298(57.53)$ \\
\hline Negative & $172(33.20)$ \\
\hline Unknown & $48(9.27)$ \\
\hline \multicolumn{2}{|l|}{ Age of onset } \\
\hline$\leq 35$ & $46(8.88)$ \\
\hline$>35$ & 472 (91.12) \\
\hline \multicolumn{2}{|l|}{ Menopausal } \\
\hline Premenopause & 255 (49.23) \\
\hline Postmenopause & $163(31.47)$ \\
\hline Unknown & $100(19.31)$ \\
\hline
\end{tabular}

$L N$ lymph node, ER estrogen receptor, $P R$ progesterone receptor, Her-2 human epidermal growth factor receptor 2, Ki-67 monoclonal antibody Ki-67

\section{Association between genotypes and breast cancer risk}

The genotypic and allelic distributions of all four SNPs are summarized in Table 2. The ancestral alleles were regarded as the reference group. In APEX1 rs3136817, we found that the heterozygous TC genotype and the $\mathrm{C}$ allele were associated with breast cancer risk (adjusted $\mathrm{OR}=0.670,95 \% \mathrm{CI}: 0.513-0.873, P=0.003$; adjusted OR $=0.729,95 \%$ CI: $0.576-0.923, P=0.009$, respectively). Moreover, a decreased breast cancer risk was conferred by the combined rs3136817 genotypes (TC + $\mathrm{CC}$ ) in the dominant model (adjusted OR $=0.682$, 95\% CI: $0.526-0.883, P=0.004)$. However, no significant differences were found for overall genotype frequencies 
Table 2 Genotype frequencies of APEX1 and OGG1 gene polymorphisms in controls and cases and their associations with breast cancer

\begin{tabular}{|c|c|c|c|c|c|}
\hline SNPS & Genotype & Case N (\%) & Control N (\%) & OR $(95 \% \mathrm{Cl})^{\mathrm{a}}$ & $P$ value \\
\hline \multicolumn{6}{|l|}{ APEX1 } \\
\hline \multirow[t]{7}{*}{ rs1130409 } & GG & $91(17.57)$ & 150(16.29) & Reference & \\
\hline & GT & $242(46.72)$ & $417(45.28)$ & $0.955(0.703-1.298)$ & 0.770 \\
\hline & $\pi$ & 185(35.71) & $354(38.44)$ & 0.864(0.629-1.187) & 0.368 \\
\hline & G & $424(40.93)$ & 717(38.93) & Reference & \\
\hline & $\mathrm{T}$ & $612(59.07)$ & $1125(61.07)$ & 0.922(0.789-1.078) & 0.309 \\
\hline & Dominant $^{b}$ & & & $0.914(0.685-1.218)$ & 0.538 \\
\hline & Recessive $^{c}$ & & & $0.894(0.714-1.119)$ & 0.328 \\
\hline \multirow[t]{7}{*}{ rs3136817 } & $\pi$ & $412(79.54)$ & $668(72.53)$ & Reference & \\
\hline & $\mathrm{TC}$ & $99(19.11)$ & $240(26.06)$ & $0.670(0.513-0.873)$ & 0.003 \\
\hline & $\mathrm{CC}$ & $7(1.35)$ & $13(1.41)$ & $0.915(0.359-2.329)$ & 0.851 \\
\hline & $\mathrm{T}$ & 923(89.09) & $1576(85.56)$ & Reference & \\
\hline & C & 113(10.91) & $266(14.44)$ & $0.729(0.576-0.923)$ & 0.009 \\
\hline & Dominant & & & $0.682(0.526-0.883)$ & 0.004 \\
\hline & Recessive & & & $1.002(0.394-2.547)$ & 0.996 \\
\hline \multicolumn{6}{|l|}{ OGG1 } \\
\hline \multirow[t]{7}{*}{ rs2072668 } & $\mathrm{CC}$ & $83(16.02)$ & $156(16.94)$ & Reference & \\
\hline & $C G$ & 253(48.84) & $440(47.77)$ & $1.072(0.786-1.461)$ & 0.661 \\
\hline & GG & $182(35.14)$ & $325(35.29)$ & $1.056(0.763-1.459)$ & 0.744 \\
\hline & C & $419(40.44)$ & 752(40.83) & Reference & \\
\hline & G & $617(59.56)$ & 1090(59.17) & $1.019(0.872-1.191)$ & 0.811 \\
\hline & Dominant & & & $1.065(0.795-1.427)$ & 0.673 \\
\hline & Recessive & & & $1.002(0.799-1.258)$ & 0.984 \\
\hline \multirow[t]{7}{*}{ rs1052133 } & $\mathrm{CC}$ & $87(16.80)$ & 154(16.72) & Reference & \\
\hline & $C G$ & $243(46.91)$ & $431(46.80)$ & $0.986(0.725-1.342))$ & 0.928 \\
\hline & GG & 188(36.29) & $336(36.48)$ & $0.985(0.715-1.356)$ & 0.925 \\
\hline & C & $417(40.25)$ & $739(40.12)$ & Reference & \\
\hline & G & 619(59.75) & $1103(59.88)$ & 0.993(0.850-1.161) & 0.934 \\
\hline & Dominant & & & 0.985(0.738-1.317) & 0.921 \\
\hline & Recessive & & & $0.995(0.795-1.246)$ & 0.966 \\
\hline
\end{tabular}

OR odds ratio, $\mathrm{Cl}$ confidence interval;

${ }^{\mathrm{a}}$ ORs were adjusted for age;

${ }^{\text {b}}$ The dominant model: comparing the combination of heterozygotes and minor allele homozygotes with the major allele homozygotes;

'The recessive model: comparing minor allele homozygotes with the combination of heterozygotes and major allele homozygotes

of rs1130409 in $A P E X 1$ and the other two SNPs (rs2072668 and rs1052133) in OGG1.

\section{Association between genotypes and clinicopathological features}

We investigated the association between the genotypes of each SNP and the clinicopathological features of the breast cancer patients, including progesterone receptor (PR), estrogen receptor (ER), P53 protein, Ki67 protein, human epidermal growth factor receptor 2 (Her-2), staging and lymph node metastasis. Only statistically significant results are presented for rs1130409 and rs2072668 in Table 3. In order to facilitate to compare data of subtype study, related data of rs3136817 which associated with the risk of breast cancer were also added in Table 3. For the APEX1 polymorphism rs1130409, the frequency of the GT and TT genotypes was increased in ER-positive patients compared with the GG genotype (adjusted $\mathrm{OR}=1.709,95 \% \mathrm{CI}: 1.028-2.842, P=0.039$; adjusted $\mathrm{OR}=1.725$, 95\% CI: $1.016-2.930, P=0.043$, respectively), and rs1130409 was also associated with ER-positive patients in the dominant model (adjusted 
Table 3 Clinicopathological features and APEX1 and OGG1 gene polymorphisms

\begin{tabular}{|c|c|c|c|c|c|c|}
\hline \multirow[t]{2}{*}{ Clinical features } & \multirow[t]{2}{*}{ SNPs } & \multirow[t]{2}{*}{ Genotype } & \multicolumn{2}{|l|}{$N(\%)$} & \multirow[t]{2}{*}{ OR $(95 \% \mathrm{Cl})^{\mathrm{a}}$} & \multirow[t]{2}{*}{$P$ value } \\
\hline & & & Positive & Negative & & \\
\hline \multicolumn{7}{|l|}{ APEX1 } \\
\hline \multirow[t]{10}{*}{$\mathrm{ER}$} & rs1130409 & GG & $48(14.55)$ & $38(22.35)$ & Reference & \\
\hline & & GT & $158(47.88)$ & $74(43.53)$ & $1.709(1.028-2.842)$ & 0.039 \\
\hline & & $\pi$ & 124(37.58) & $58(34.12)$ & $1.725(1.016-2.930)$ & 0.043 \\
\hline & & Dominant $^{\mathrm{b}}$ & & & $1.716(1.068-2.759)$ & 0.026 \\
\hline & & Recessive $^{c}$ & & & $1.174(0.796-1.732)$ & 0.417 \\
\hline & rs3136817 & $\pi$ & 267(80.91) & $130(76.47)$ & Reference & \\
\hline & & TC & $59(17.88)$ & $37(21.76)$ & $0.779(0.491-1.236)$ & 0.288 \\
\hline & & $\mathrm{CC}$ & $4(1.21)$ & $3(1.76)$ & $0.673(0.148-3.063)$ & 0.608 \\
\hline & & Dominant & & & $0.771(0.492-1.207)$ & 0.255 \\
\hline & & Recessive & & & $0.708(0.156-3.213)$ & 0.655 \\
\hline \multirow[t]{10}{*}{ Her-2 } & rs1130409 & GG & $27(23.08)$ & $59(15.57)$ & Reference & \\
\hline & & GT & $56(47.86)$ & $176(46.44)$ & $0.689(0.399-1.190)$ & 0.182 \\
\hline & & $\pi$ & $34(29.06)$ & 144(37.99) & $0.508(0.281-0.917)$ & 0.025 \\
\hline & & Dominant & & & $0.608(0.364-1.015)$ & 0.057 \\
\hline & & Recessive & & & $0.663(0.423-1.040)$ & 0.074 \\
\hline & rs3136817 & $\pi$ & $95(81.20)$ & 298(78.63) & Reference & \\
\hline & & TC & 21(17.95) & 75(19.79) & $0.875(0.512-1.497)$ & 0.627 \\
\hline & & $C C$ & $1(0.85)$ & $6(1.58)$ & $0.505(0.060-4.265)$ & 0.531 \\
\hline & & Dominant & & & $0.848(0.501-1.433)$ & 0.537 \\
\hline & & Recessive & & & $0.519(0.062-4.365)$ & 0.546 \\
\hline \multirow[t]{5}{*}{ Ki-67 } & rs3136817 & $\pi$ & 239(80.20) & 134(77.91) & Reference & \\
\hline & & TC & $54(18.12)$ & $36(20.93)$ & $0.842(0.525-1.350)$ & 0.475 \\
\hline & & CC & $5(1.68)$ & $2(1.16)$ & $1.451(0.277-7.610)$ & 0.660 \\
\hline & & Dominant & & & $0.873(0.552-1.383)$ & 0.564 \\
\hline & & Recessive & & & $1.502(0.287-7.854)$ & 0.630 \\
\hline \multicolumn{7}{|l|}{ OGG1 } \\
\hline \multirow[t]{5}{*}{$\mathrm{Ki}-67$} & rs2072668 & $\mathrm{CC}$ & $55(18.46)$ & $21(12.21)$ & Reference & \\
\hline & & CG & 146(48.99) & $82(47.67)$ & $0.675(0.381-1.195)$ & 0.178 \\
\hline & & GG & $97(32.55)$ & $69(40.12)$ & $0.536(0.297-0.968)$ & 0.039 \\
\hline & & Dominant & & & $0.612(0.355-1.052)$ & 0.076 \\
\hline & & Recessive & & & $0.913(0.620-1.344)$ & 0.644 \\
\hline
\end{tabular}

ER estrogen receptor, Her-2 human epidermal growth factor receptor 2, Ki-67 monoclonal antibody Ki-67, OR odds ratio, Cl confidence interval; ${ }^{a}$ ORs were adjusted for age;

${ }^{\mathrm{b}}$ The dominant model: comparing the combination of heterozygotes and minor allele homozygotes with the major allele homozygotes;

'The recessive model: comparing minor allele homozygotes with the combination of heterozygotes and major allele homozygotes

OR $=1.716,95 \%$ CI: $1.068-2.759, P=0.026)$. Furthermore, compared with the GG genotype, the TT homozygous genotype frequency was decreased in Her-2-positive patients (adjusted OR $=0.508$, 95\% CI: $0.281-0.917$, $P=0.025)$. For the OGG1 polymorphism rs2072668, compared with the CC genotype, the homozygous GG genotype showed a reduced frequency in Ki-67positive patients (adjusted OR $=0.536,95 \% \mathrm{CI}: 0.297$ 0.968, $P=0.039)$.

\section{Haplotype analyses}

We further investigated haplotype frequencies in the patients and controls. Only haplotypes with a frequency greater than $5 \%$ are presented in Table 4 . In this combination, haplotype CT in APEX1 had a lower frequency in patients compared with controls. After applying the Bonferroni multiple adjustment, only one significant $P$ value was observed at the APEX1 CT haplotype $(P<0.001)$, indicating a significant difference. 
Table 4 Frequency distributions of haplotypes of APEX1 and OGG1 in cases and controls

\begin{tabular}{|c|c|c|c|c|c|}
\hline Haplotype & Case (freq\%) & Control (freq\%) & $P$ value ${ }^{c}$ & OR (95\% Cl) & $P C$ \\
\hline \multicolumn{6}{|l|}{$\overline{A P E X 1^{a}}$} \\
\hline$C G$ & 94.19 (9.10\%) & 179.03 (9.70\%) & 0.581 & $0.929(0.715-1.207)$ & NS \\
\hline$C T$ & $18.81(1.80 \%)$ & 86.97 (4.70\%) & $7.10 \mathrm{e}-05$ & $0.373(0.225-0.618)$ & $<0.001$ \\
\hline TG & 329.81 (31.80\%) & 537.97 (29.2\%) & 0.140 & $1.132(0.960-1.335)$ & NS \\
\hline GG & 593.19 (57.30\%) & $1038.03(56.40 \%)$ & 0.639 & $1.038(0.890-1.210)$ & NS \\
\hline \multicolumn{6}{|l|}{$O G G 1^{b}$} \\
\hline CC & 403.81 (39.00\%) & 728.87 (39.60\%) & 0.908 & $0.991(0.847-1.159)$ & NS \\
\hline CG & 15.19 (1.50\%) & $23.13(1.30 \%)$ & - & - & NS \\
\hline $\mathrm{GC}$ & $13.19(1.30 \%)$ & $10.13(0.50 \%)$ & - & - & NS \\
\hline GG & 603.81 (58.3\%) & 1079.87 (58.6\%) & 0.908 & $1.009(0.862-1.181)$ & NS \\
\hline
\end{tabular}

$P C$ corrected $P$ value (after Bonferroni multiple adjustment), $O R$ odds ratio, $C l$ confidence interval, NS not significant

${ }^{\text {a }}$ The order of SNPs in APEX1 is rs3136817 and rs1130409

${ }^{\mathrm{b}}$ The order of SNPs in OGG1 is rs2072668 and rs1052133

${ }^{c} P$ value calculated by Fisher's exact test

In addition, no statistically significant differences between controls and patients were observed in the frequencies of other APEX1 and OGG1 haplotypes.

\section{Interaction analysis}

We further adopted the analytical method of MDR data mining to examine the potential interactions among the four polymorphisms within the APEX1 and OGG1 genes. Table 5 shows the best interaction models identified by the MDR analysis, with testing balance accuracy (TBA) and cross-validation consistency. APEX1 rs 3136817 , as the best one-locus model, had the maximum testing-balanced accuracy (0.5323) and maximum consistency (100\%) among the four SNPs. A four-locus model (rs2072668, rs1052133, rs3136817 and rs1130409) also exhibited maximum consistency (100\%), but its TBA (0.5029) was lower than that of the one-locus model. Moreover, the combination of rs3136817 and rs2072668 formed the best twolocus model, with a high TBA (0.5291) and CVC (70\%), among all combinations of two SNPs. The combination of rs3136817, rs2072668 and rs1130409 produced the best three-locus model, with a high TBA (0.5044) and CVC (90\%), among all pair-wise combination of three SNPs.

Table 5 MDR interaction analysis between SNP-SNP

\begin{tabular}{llll}
\hline Each overall best model & $\begin{array}{l}\text { Testing Balance } \\
\text { Accuracy }\end{array}$ & CVC $^{\text {a }}$ & $P$ Value $^{b}$ \\
\hline One-locus: rs3136817 & 0.5323 & $10 / 10$ & 0.1419 \\
$\begin{array}{l}\text { Two-locus: One-locus } \\
\text { plus rs2072668 }\end{array}$ & 0.5291 & $7 / 10$ & 0.3846 \\
$\begin{array}{l}\text { Three-locus: Two-locus } \\
\text { plus rs1130409 }\end{array}$ & 0.5044 & $9 / 10$ & 0.7383 \\
$\begin{array}{l}\text { Four-locus: Three-locus } \\
\text { plus rs 1052133 }\end{array}$ & 0.5029 & $10 / 10$ & 0.7502 \\
\hline
\end{tabular}

${ }^{a}$ CVC cross-validation consistency

${ }^{\mathrm{b}} P$-values as calculated after 1000 permutations
However, no significant association was observed for these interaction models out of 1000 permutations.

\section{Discussion}

Genetic polymorphisms in key genes involved in DNA repair may influence DNA damage response, carcinogenesis and DNA repair capacity. Polymorphic variants have been confirmed to be good candidates for assessing cancer risk. We estimated the relationship between APEX1 and OGG1 gene polymorphisms and breast cancer risk among 1430 Han women of Northwest China in this experiment using a tag SNP-based study. The key finding was that the APEX1 polymorphism rs3136817 might mediate synergistic and independent effects on breast carcinogenesis. We found that the rs3136817 heterozygous TC genotype and the combined genotype $(\mathrm{TC}+\mathrm{CC})$ were associated with decreased breast cancer risk.

DNA excision repair capacity is known to play a crucial role in carcinogenesis [27]. If changes that occur in the DNA sequence due to copying errors are not corrected, they may ultimately interfere with cell function. Damaged or inappropriate bases can be repaired by several mechanisms. The BER pathway is considered the primary mechanism involved in protecting against gene mutations and repairing DNA damage, and APEX1 and OGG1 are key components of this pathway. The BER proteins encoded by these genes act in a highly coordinated manner at the site of DNA damage. For example, repair of 8-oxoguanine, an oxidized base, is initiated by the OGG1 glycosylase, which recognizes and removes damaged bases, forming an apurinic site that is cleaved by APEX1. The resulting single-strand break can be subsequently repolymerized by DNA ligase 3 and polymerase $\beta$ [28]. According to our current results, patients carrying the rs3136817 TC genotype had a reduced breast cancer risk, implying that heterozygosity at rs3136817 
may have a positive influence on DNA repair capacity in DNA damage responsive pathways and thus potentially prevent breast cancer. Similar results were observed in bladder cancer and lung cancer. Nevertheless, this protection was not observed in individuals carrying other SNPs. Similar researches were only reported in bladder cancer and lung cancer. Zhu et al. [29] reported that APEX1 rs3136817 TC genotype was associated with a decreased risk of bladder cancer. However, Li et al. [30] demonstrated that no association between APEX1 rs3136817 and the risk of radiation-induced pneumonitis grade $\geq 3$. Our study is the first to demonstrate that the rs3136817 heterozygous genotype was associated with a decreased risk of breast cancer. Of all the SNPs assessed, the rs1130409 and rs1052133 polymorphisms showed the most consistent relationship to breast cancer in two previous reports, demonstrating that these variations have no significant impact on breast cancer risk $[18,31]$. However, a few reports which were different from our results also indicated that breast cancer risk was significantly associated with APEX1 rs1130409 in North Indian [32], Korean [17] and Caucasian [19] women. To the best of our knowledge, the rs3136817 polymorphic locus has not been previously evaluated regarding its association with cancer, except for bladder cancer and lung cancer. Moreover, the possibility that the associations noted above might have occurred by chance cannot be excluded. Further evidence in different regional populations and larger sample sizes, in addition to functional studies, are required to reinforce these results.

We further found that the APEX1 rs1130409 GT and TT genotypes were increased in ER-positive patients by analyzing the association of clinicopathological features with the four SNPs, suggesting that these genotype carriers exhibited adverse clinicopathological features of breast cancer and failed to benefit from endocrine therapy. In addition, a lower frequency of women carrying the TT genotype was Her-2 positive. Her-2 is a ligand-less member of the human epidermal growth factor receptor family. Approximately $15 \%$ of patients with breast cancer exhibit Her-2 over-expression, which is associated with invasive behavior, unresponsiveness to common endocrine therapies, poor prognosis and reduced survival [33, 34]. For OGG1, the rs2072668 polymorphism was also associated with the pathologic characteristics of patients. The rs2072668 homozygous GG genotype carriers had a reduced frequency of Ki-67-positive expression. The $\mathrm{Ki}-67$ protein is a nuclear marker of cell proliferation that is expressed at high levels in breast cancer patients, and increased expression is associated with worse outcomes $[35,36]$. Recent studies have indicated that longterm outcomes may be predicted by changes in Ki-67 expression after endocrine treatment [37]. Therefore, our current results indicate that the APEX1 rs1130409
TT genotype and the OGG1 rs2072668 GG genotype deficiencies may lead to poorer prognosis and reduced survival.

In our study, the associations between breast cancer risk and haplotypes were also assessed. The APEX1 haplotype containing C-T (alleles rs3136817 and rs1130409) was observed at a higher frequency in the controls. Consequently, we infer that the APEX1 CT haplotype may be involved in decreasing the risk of breast cancer. MDR analysis has been used to examine the interactions of multiple genes in common diseases as a promising data-mining approach because it easily overcomes some of the limitations and inadequacies of traditional statistics, such as logistic regression, to characterize and examine gene-gene and gene-environment interactions. Meanwhile, a four-locus interaction associated with cumulative breast cancer risk was identified by MDR analysis. However, the four-locus best interaction model did not exhibit significant improvements compared with the other models in this case. The main effect model of rs3136817 performed best, which implies that the APEX1 rs3136817 polymorphism is a powerful risk factor and may play an important role in the interaction with other SNPs in affecting breast cancer development, either synergistically or antagonistically. Nevertheless, no statistical significance was observed, and evidence is therefore needed to support the hypothesis of SNP-SNP interactions in the future.

\section{Conclusions}

In summary, our data provide clear evidence that the rs3136817 polymorphism in APEX1 and a corresponding haplotype may be involved in breast cancer risk in the Han women of Northwest China. Notably, the rs3136817 heterozygous variant exhibited enhancement in the major DNA repair pathway, and this capacity may prevent the early development of breast cancer. As far as we know, this study is the latest to report that the APEX1 rs3136817 genotype is associated with cancer risk. The findings further suggest that the combined effect of SNPs determines the individual women's risk for breast cancer. A better understanding of the mechanism of carcinogenesis will facilitate improved, individualized pharmaceutical therapy for patients with breast cancer and the implementation of breast cancer prevention strategies.

\section{Additional file}

Additional file 1: A questionnaire survey of breast health. Questionnaire included participant's eating habits, living environment, lifestyle, smoking, physiological state, reproductive condition, past medical history and family history of cancer. (PDF 415 kb)

\section{Abbreviations}

APEX1: Apurinic/apyrimidinic endonuclease 1; BER: Base excision repair; Cls: Confidence intervals; CVC: Cross-validation consistency; ER: Estrogen 
receptor; GWAS: Genome-wide association studies; Her-2: Human epidermal growth factor receptor 2; HWE: Hardy-Weinberg equilibrium; MDR: Multifactor dimensionality reduction; NCCR: National Central Cancer Registry; NER: Nucleotide excision repair; NTC: Non-template control; OGG1: 8-oxoguanine DNA glycosylase 1; ORs: Odds ratios; PR: Progesterone receptor; SD: Standard deviation; SNPs: Single nucleotide polymorphisms; TBA: Testing balance accuracy

\section{Acknowledgments}

We wish to thank all the patients and healthy volunteers for providing blood samples. We also thank the nurses, clinical researchers and regulatory coordinators at the Department of Breast Surgery and Research Center of Translational Medicine at Gansu Provincial Cancer Hospital for their collaboration.

\section{Funding}

This study was supported by the 11th batch Science and Technology Support Project of Gansu Province of China (Grant No. 1011FKCA089) and Gansu province science and technology project (Grant No. 17JR3TA013).

\section{Availability of data and materials}

The clinical raw datasets used and/or analyzed during the current study will be available from corresponding author due to some patient confidentiality.

\section{Authors' contributions}

The conception and design of study: TW and HS. Performed the experiments: TW, HW, HuG, LW, GZ and YZ. Performed breast ultrasound and X-ray examination, patient's recruitment and collected the clinical data: SY, HoG and BZ. Extracted genomic DNA and helped with the analysis of questionnaire data: XZ and HL. Designed primers and performed DNA sequencing: HZ. Performed the statistical analyses: TW and HZ. Drafting the article or revising it critically for the intellectual content: TW, HW and HS. All authors read and approved the final manuscript.

\section{Ethics approval and consent to participate}

All related data were drawn from questionnaires and the patients' medical charts. Informed consent was obtained from all individual participants, and this research was approved by the Ethical Committee of the Gansu Provincial Academic Institute for Medical Research and Gansu Provincial Cancer Hospital, IRB number A201412040036 (approved on December 04, 2014).

\section{Competing interest}

The authors declare that they have no competing interests.

\section{Publisher's Note}

Springer Nature remains neutral with regard to jurisdictional claims in published maps and institutional affiliations.

\section{Author details}

${ }^{1}$ Research Center of Translational Medicine, Gansu Provincial Academic Institute for Medical Research, NO. 2 Xiaoxihu East Street, Lanzhou, Gansu 730050, People's Republic of China. ²Department of Breast Surgery, Gansu Provincial Cancer Hospital, Lanzhou, Gansu 730050, People's Republic of China.

\section{Received: 5 October 2017 Accepted: 18 April 2018}

\section{Published online: 02 May 2018}

\section{References}

1. Zeng H, Zheng R, Guo Y, Zhang S, Zou X, Wang N, et al. Cancer survival in China, 2003-2005: a population-based study. Int J Cancer. 2015;136(8):1921-30. https://doi.org/10.1002/ijc.29227.

2. Chen $W$, Zheng $\mathrm{R}$, Zeng $\mathrm{H}$, Zhang $\mathrm{S}, \mathrm{He} J$. Annual report on status of cancer in China, 2011. Chin J Cancer Res. 2015;27(1):2-12. https://doi.org/10.3978/j. issn.1000-9604.2015.01.06

3. King MC, Marks JH, Mandell JB, New York Breast Cancer Study Group. Breast and ovarian cancer risks due to inherited mutations in BRCA1 and BRCA2. Science. 2003;302(5645):643-6. https://doi.org/10.1126/science.1088759.

4. Kang PC, Phuah SY, Sivanandan K, Kang IN, Thirthagiri E, Liu JJ, et al. Recurrent mutation testing of BRCA1 and BRCA2 in Asian breast cancer patients identify carriers in those with presumed low risk by family history. Breast Cancer Res Treat. 2014;144(3):635-42. https://doi.org/10. 1007/s10549-014-2894-X.
5. Liede A, Narod SA. Hereditary breast and ovarian cancer in Asia: genetic epidemiology of BRCA1 and BRCA2. Hum Mutat. 2002;20(6):413-24. https:// doi.org/10.1002/humu.10154.

6. Menashe I, Maeder D, Garcia-Closas M, Figueroa JD, Bhattacharjee S, Rotunno $\mathrm{M}$, et al. Pathway analysis of breast cancer genome-wide association study highlights three pathways and one canonical signaling cascade. Cancer Res. 2010;70(11):4453-9. https://doi.org/10.1158/0008-5472.CAN-09-4502.

7. Pharoah PD, Antoniou A, Bobrow M, Zimmern RL, Easton DF, Ponder BA. Polygenic susceptibility to breast cancer and implications for prevention. Nat Genet. 2002;31(1):33-6. https://doi.org/10.1038/ng853.

8. Long J, Cai Q, Sung H, Shi J, Zhang B, Choi JY, et al. Genome-wide association study in east Asians identifies novel susceptibility loci for breast cancer. PLoS Genet. 2012;8(2):e1002532. https://doi.org/10.1371/journal. pgen. 1002532.

9. Li J, Humphreys K, Heikkinen T, Aittomaki K, Blomqvist C, Pharoah PD, et al. A combined analysis of genome-wide association studies in breast cancer. Breast Cancer Res Treat. 2011;126(3):717-27. https://doi.org/10.1007/s10549010-1172-9.

10. Torgovnick A, Schumacher B. DNA repair mechanisms in cancer development and therapy. Front Genet. 2015;6:157. https://doi.org/10.3389/ fgene.2015.00157.

11. Matta J, Echenique M, Negron E, Morales L, Vargas W, Gaetan FS, et al. The association of DNA Repair with breast cancer risk in women. A comparative observational study. BMC Cancer. 2012;12:490. https://doi. org/10.1186/1471-2407-12-490.

12. Yuan SS, Hou MF, Hsieh YC, Huang CY, Lee YC, Chen YJ, et al. Role of MRE11 in cell proliferation, tumor invasion, and DNA repair in breast cancer. J Natl Cancer Inst. 2012;104(19):1485-502. https://doi.org/10.1093/jnci/djs355.

13. Chaudhry MA. Base excision repair of ionizing radiation-induced DNA damage in G1 and G2 cell cycle phases. Cancer Cell Int. 2007;7:15. https:// doi.org/10.1186/1475-2867-7-15.

14. Jung HJ, Kim HL, Kim YJ, Weon Jl, Seo YR. A novel chemopreventive mechanism of selenomethionine: enhancement of APE1 enzyme activity via a Gadd45a, PCNA and APE1 protein complex that regulates p53mediated base excision repair. Oncol Rep. 2013;30(4):1581-6. https://doi. org/10.3892/or.2013.2613.

15. Horton JK, Stefanick DF, Prasad R, Gassman NR, Kedar PS, Wilson SH. Base excision repair defects invoke hypersensitivity to PARP inhibition. Mol Cancer Res. 2014;12(8):1128-39. https://doi.org/10.1158/1541-7786.MCR-13-0502.

16. Karahalil B, Bohr VA, Wilson DM 3rd. Impact of DNA polymorphisms in key DNA base excision repair proteins on cancer risk. Hum Exp Toxicol. 2012; 31(10):981-1005. https://doi.org/10.1177/0960327112444476.

17. Kim KY, Han W, Noh DY, Kang D, Kwack K. Impact of genetic polymorphisms in base excision repair genes on the risk of breast cancer in a Korean population. Gene. 2013;532(2):192-6. https://doi.org/10.1016/j. gene.2013.09.069.

18. Roberts MR, Shields PG, Ambrosone CB, Nie J, Marian C, Krishnan SS, et al. Single-nucleotide polymorphisms in DNA repair genes and association with breast cancer risk in the web study. Carcinogenesis. 2011;32(8):1223-30. https://doi.org/10.1093/carcin/bgr096.

19. Smith TR, Levine EA, Freimanis Rl, Akman SA, Allen GO, Hoang KN, et al. Polygenic model of DNA repair genetic polymorphisms in human breast cancer risk. Carcinogenesis. 2008;29(11):2132-8. https://doi.org/10.1093/ carcin/bgn193.

20. Wang T, Wang H, Guo H, Yang S, Zhu G, Guo H, et al. Polymorphisms in the DNA repair gene ERCC2/XPD and breast cancer risk: a HapMap-based case-control study among Han Women in a Chinese less-developed area. Genet Test Mol Biomarkers. 2014;18(10):703-10. https://doi.org/10.1089/gtmb.2014.0028.

21. Gabriel SB, Schaffner SF, Nguyen H, Moore JM, Roy J, Blumenstiel B, et al. The structure of haplotype blocks in the human genome. Science. 2002; 296(5576):2225-9. https://doi.org/10.1126/science.1069424.

22. Xu F, Li D, Zhang Q, Fu Z, Yuan W, Pang D, et al. Association of CD27 and CD70 gene polymorphisms with risk of sporadic breast cancer in Chinese women in Heilongjiang Province. Breast Cancer Res Treat. 2012;133(3):110513. https://doi.org/10.1007/s10549-012-1987-7.

23. Li Z, Zhang Z, He Z, Tang W, Li T, Zeng Z, et al. A partition-ligationcombination-subdivision EM algorithm for haplotype inference with multiallelic markers: update of the SHEsis (http://analysis.bio-x.cn). Cell Res. 2009;19(4):519-23. https://doi.org/10.1038/cr.2009.33.

24. Shi YY, He L. SHEsis, a powerful software platform for analyses of linkage disequilibrium, haplotype construction, and genetic association 
at polymorphism loci. Cell Res. 2005;15(2):97-8. https://doi.org/10.1038/ sj.cr.7290272.

25. Namkung J, Kim K, Yi S, Chung W, Kwon MS, Park T. New evaluation measures for multifactor dimensionality reduction classifiers in gene-gene interaction analysis. Bioinformatics. 2009;25(3):338-45. https://doi.org/10. 1093/bioinformatics/btn629.

26. Hahn LW, Ritchie MD, Moore JH. Multifactor dimensionality reduction software for detecting gene-gene and gene-environment interactions. Bioinformatics. 2003;19(3):376-82.

27. Deng L, Kimmel M, Foy M, Spitz M, Wei Q, Gorlova O. Estimation of the effects of smoking and DNA repair capacity on coefficients of a carcinogenesis model for lung cancer. Int J Cancer. 2009;124(9):2152-8. https://doi.org/10.1002/ijc.24149.

28. Sangrajrang S, Schmezer P, Burkholder I, Waas P, Boffetta P, Brennan P, et al. Polymorphisms in three base excision repair genes and breast cancer risk in Thai women. Breast Cancer Res Treat. 2008;111(2):279-88. https://doi.org/10. 1007/s10549-007-9773-7.

29. Zhu G, Su H, Lu L, Guo H, Chen Z, Sun Z, et al. Association of nineteen polymorphisms from seven DNA repair genes and the risk for bladder cancer in gansu province of China. Oncotarget. 2016; https://doi.org/10. 18632/oncotarget.9146.

30. Li H, Liu G, Xia L, Zhou Q, Xiong J, Xian J, et al. A polymorphism in the DNA repair domain of APEX1 is associated with the radiation-induced pneumonitis risk among lung cancer patients after radiotherapy. Br J Radiol. 2014;87(1040): 20140093. https://doi.org/10.1259/bjr.20140093.

31. Chang-Claude J, Ambrosone CB, Lilla C, Kropp S, Helmbold I, von Fournier $D$, et al. Genetic polymorphisms in DNA repair and damage response genes and late normal tissue complications of radiotherapy for breast cancer. $\mathrm{Br} J$ Cancer. 2009;100(10):1680-6. https://doi.org/10.1038/sj.bjc.6605036.

32. Mitra AK, Singh N, Singh A, Garg VK, Agarwal A, Sharma M, Chaturvedi R, Rath SK. Association of polymorphisms in base excision repair genes with the risk of breast cancer: a case-control study in North Indian women. Oncol Res. 2008:17(3):127-35.

33. Wolff AC, Hammond ME, Hicks DG, Dowsett M, McShane LM, Allison KH, et al. Recommendations for human epidermal growth factor receptor 2 testing in breast cancer: American Society of Clinical Oncology/College of American Pathologists clinical practice guideline update. J Clin Oncol. 2013; 31(31):3997-4013. https://doi.org/10.1200/JCO.2013.50.9984.

34. Cheang MC, Chia SK, Voduc D, Gao D, Leung S, Snider J, et al. Ki67 index, HER2 status, and prognosis of patients with luminal B breast cancer. J Natl Cancer Inst. 2009;101(10):736-50. https://doi.org/10.1093/jnci/djp082.

35. de Azambuja E, Cardoso F, de Castro G Jr, Colozza M, Mano MS, Durbecq V, et al. Ki-67 as prognostic marker in early breast cancer: a meta-analysis of published studies involving 12,155 patients. Br J Cancer. 2007;96(10):1504-13. https://doi.org/10.1038/sj.bjc.6603756.

36. Trihia H, Murray S, Price K, Gelber RD, Golouh R, Goldhirsch A, et al. Ki-67 expression in breast carcinoma: its association with grading systems, clinical parameters, and other prognostic factors-a surrogate marker? Cancer. 2003: 97(5):1321-31. https://doi.org/10.1002/cncr.11188.

37. Dowsett M, Smith IE, Ebbs SR, Dixon JM, Skene A, A'Hern R, et al. Prognostic value of Ki67 expression after short-term presurgical endocrine therapy for primary breast cancer. J Natl Cancer Inst. 2007;99(2):167-70. https://doi.org/ 10.1093/jnci/djk020.

\section{Ready to submit your research? Choose BMC and benefit from:}

- fast, convenient online submission

- thorough peer review by experienced researchers in your field

- rapid publication on acceptance

- support for research data, including large and complex data types

- gold Open Access which fosters wider collaboration and increased citations

- maximum visibility for your research: over $100 \mathrm{M}$ website views per year

At BMC, research is always in progress.

Learn more biomedcentral.com/submissions 